\title{
After Windscale, what?
}

THE report by Mr Justice Parker into British Nuclear Fuels Ltd's application to extend reprocessing facilities at Windscale breaks much new ground. Not only was the inquiry on an exceptionally broad scale, bringing into an ostensibly local affair all the questions of national interest, but now the government has had to find a way of opening the report up for public debate without seeming to contravene the principle that $\mathrm{Mr}$ Peter Shore, Secretary of State for the Environment, should, as is normal in planning inquiries, make up his mind on the basis of his inspector's report alone, free from any further hectoring, adducing of 'new evidence' and so on. This particular circle has been squared by the subterfuge described on page 117; $\mathrm{Mr}$ Shore has said that it is a cogent and persuasive report but has gone against its line of argument in rejecting the application, simply to allow parliamentary debate.

But, as pointed out on page 115 this is not the end of a planning road so much as the beginning of one. Large-scale investment in energy facilities is just round the corner for all manner of technologies-alternative as well as traditional-and in each case the questions to be raised stretch to the limit the forms of inquiry and the conventions applied to them at present. And not only must there be doubts about the shape of future inquiries, there must also be serious questions about the extent of public participation. The British public-even those who would regard themselves as intelligent laymen'--is not particularly well informed on matters of energy and energy policy, in part because of the compartmentalisation of British society, in part because there has been a long-standing trust in the quality of the expert. As yet we not only do not know what the intelligent layman thinks about nuclear issues, we do not know whether the intelligent layman even wants to express a view on these matters.

The next nuclear decision to be taken will come within a year when the Atomic Energy Authority puts up a proposal for the building of CFR 1, a demonstration commercial fast breeder reactor, which is possibly planned for the Windscale site. The planning inquiry format, such as was followed at Windscale, is ideal, no doubt, for purely local matters but is not ideal when matters of national interest are also being debated. Fortunately there already exists on the statute books the concept of the Planning Inquiry Commission in which, say, five commissioners, not necessarily with legal training, hear evidence (including the cross-examination of witnesses) and can initiate their own research. It is envisaged that Planning Inquiry Commissions would consist of two stages, the first of which looked at the broad issues of whether the need existed, the second of which looked at the local impact. The Roskill Commission on the Third London Airport was the closest in style so far to a Planning Inquiry Commission, but one is almost certain to be called over the exploitation of the Vale of Belvoir coalfield.

It can be argued, however, that even a Planning Inquiry Commission does not do the job adequately, as it is dissolved on completing its work (the Minister is still, of course, at liberty to reject its recommendations). What is needed is some sort of standing commission that does not have to be re-educated each time a new decision has to be made-and yet it must not become a group whose views become hardened and utterly predictable. (It should be added that the recently announced Commission on Energy and the Environment is specifically excluded from studying individual planning applications so is not an appropriate body.)

But what about public participation, particularly in the question of CFR1? Commissions may be fine in many respects but they do consist largely of experts talking to each other. There is a strong case for the Commons Select Committee on Science and Technology picking up this issue in order to try and stimulate more parliamentary interest in energy matters than has so far been apparent. Certainly it would prove the most difficult venture the committee had yet undertaken and certainly its deliberations could hardly be a replacement for the standard planning procedures. And yet, if it proceeded with some dispatch it might well provide much of the relevant background, and if hearings were conducted imaginatively it could well play a major role in raising the interest of public and politicians. 